\title{
Atypical progressive supranuclear palsy syndrome
}

INSERM

\section{Source}

INSERM. (1999). Orphanet: an online rare disease and orphan drug data base. Atypical progressive supranuclear palsy syndrome. ORPHA:99750

Atypical prog ressive supranuclear palsy (atypical PSP) is a group of clinical syndromes associated with underlying PSP-tau pathology, that do not conform to the classic presentation of PSP (Richardson syndrome; see this term), a rare late-onset neurodegenerative disease. The group comprises PSP-Parkinsonism (PSP-P), PSP-Pure akinesia with gait freezing (PSP-PAGF), PSP-corticobasal syndrome (PSP-CBS) and PSPprogressive non fluent aphasia (PSP-PNFA) (see these terms). 